\title{
Clinical guideline writers often conflicted
}

$\mathrm{R}$ arely a week goes by without a medical society releasing a new or updated set of clinical practice guidelines. The National Guideline Clearinghouse, a program run by the United States government that aggregates guidelines from around the world, currently has a list of 360 guidelines in progress. The American College of Radiology alone is working on 30 new guidelines.

In the fine print at the back of most of these guidelines, at least the ones published in well-regarded medical journals, is a paragraph that discloses the competing interests of the people who wrote them. Some medical researchers believe there is too little attention being paid to these conflicts of interest.

Dr. Niteesh Choudhry, an assistant professor at Harvard Medical School in Boston, Massachusetts, says close examination indicates a high rate of interaction between guideline writers and pharmaceutical companies.

"The short version is that an overwhelmingly large portion of guideline authors have some relationship with industry," says Choudhry.

For example, consider the Canadian Thoracic Society's (CTS) 2010 guidelines on asthma management for adults and children ages six and above (Can Respir J 2010;17:15-24). Funding for the guidelines was provided by several drug companies, including AstraZeneca Canada, GlaxoSmithKline Inc. Canada and Merck Frosst Canada.

"Collectively, the physicians on the CTS Asthma Committee have on at least one occasion acted as consultants for, received research funds from, and received speaker's fees from these pharmaceutical companies," the guidelines state.

According to Choudhry, conflicts of interest such as these are worth examining because guidelines have the potential to affect large numbers of patients. "Clinical guidelines are massively influential," he says. "They are used by numerous physicians."

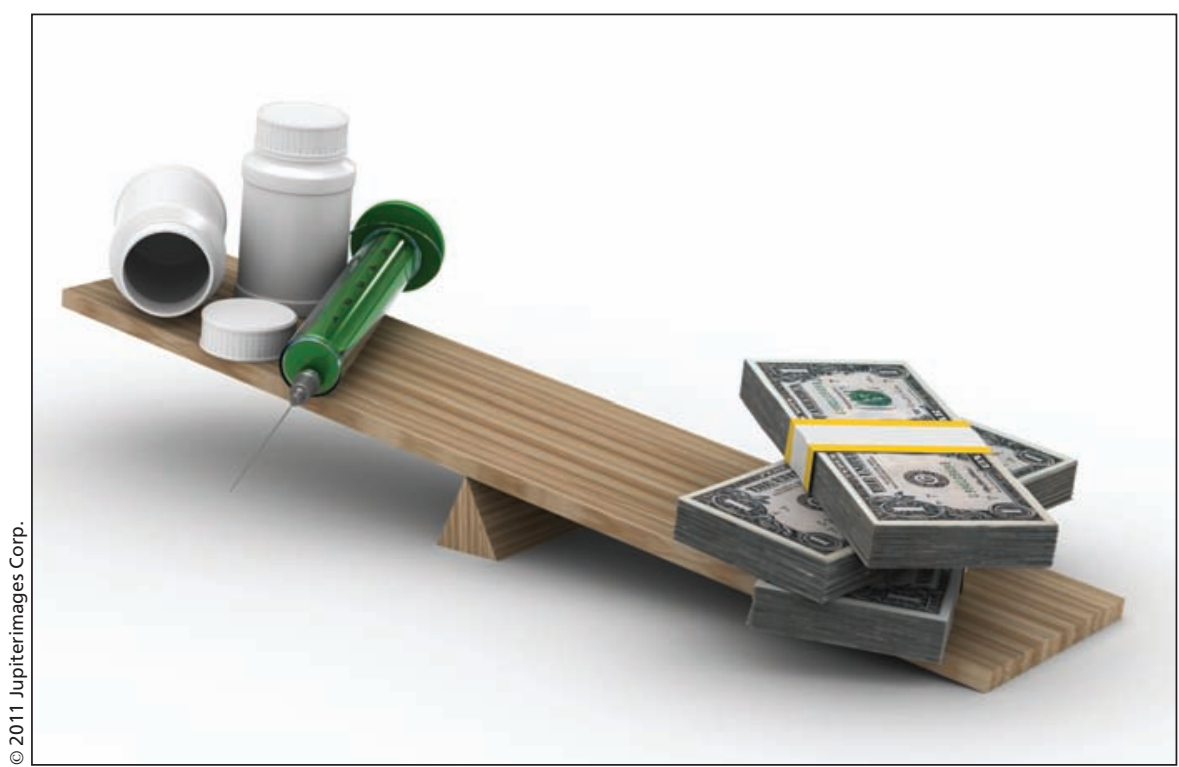

Guideline writers underestimate the potential influence that ties to industry could have on their recommendations, experts say.

Physicians have to rely on guidelines, says Dr. Joel Lexchin, a professor at York University's School of Health Policy and Management, in Toronto, Ontario. "Given the amount of medical evidence out there, no one doctor can know all the evidence in the field."

Disclosing conflicts of interest in guidelines is an important step in creating transparency, but disclosure does not eliminate potential biases, says Lexchin. "If I'm not an expert, how do I know the influence of the conflicts of interest? They could have no influence or they could be very influential. I have no basis for judging that. And if I were an expert, I probably wouldn't need the guidelines."

Choudry says that many guideline writers underestimate the potential influence that ties to industry could have on their recommendations. Choudry and colleague surveyed guideline authors and found that $87 \%$ had ties with drug companies, and 59\% had relationships with companies whose drugs were considered in the guidelines they helped create (JAMA 2002;287:612-7).

"We wonder whether academicians and physicians underestimate the impact of relationships on their actions because the nature of their professions is the pursuit of objective unbiased information," the paper states. "Unfortunately, bias may occur both consciously and subconsciously, and therefore, its influence may go unrecognized."

Choudhry is quick to point out, however, that banning people with ties to industry from participating in the creation of clinical guidelines is not realistic. "It's a bit more complicated than saying just because you have a relationship with industry therefore you are biased," he says. "The people most likely to have those relationships are also the people who are the experts and are most widely published."

But neither is it sufficient to simply disclose relationships with industry and leave it at that, suggests Choudhry. A better approach would be to work on defining which types of relationships have the most potential to introduce bias. For instance, a guideline writer who holds stock in a company that makes a drug or medical device mentioned in the guidelines has a strong conflict of interest. The potential for bias is probably less, however, if a 
guideline writer works for an institution that has received unrestricted research grants from industry.

"We need to have an approach where we look at which types of rela- tionships are permissible and which aren't, and not say that disclosure alone will solve the problem," says Choudhry. "It doesn't mean excluding all relationships with industry but we should be sensitive that conflicts of interest can have real impact." - Roger Collier, CMAJ

CMAJ 2011. DOI:10.1503/cmaj.109-3757 